Networking Knowledge: Journal of the MeCCSA Postgraduate Network, Vol. 4, No. 1 (2011)

ARTICLE

\title{
"Please Baby, take me Back" Homo-social bonds in the Contemporary British Biopic
}

\author{
MATTHEW ROBINSON, University of the West of England
}

\begin{abstract}
Using textual analysis, this article offers a comparison between the homo-social bonds represented in The Damned United and those in The King's Speech. The article traces a pattern in which a powerful and dominant male suffers a professional crisis which is only overcome through the support of an intimate male friendship that is fixed as heterosexual though marginalised female figures. In both films, the central characters are rehabilitated into success only after a humbling and emotional acceptance of their need for support that positions them within the terms of 'new man-ism'. However, because this is couched through homo-social couplings, rather than the heterosexual, the films mark the hybridisation of machismo and 'new man-ism' that were previously seen as alternative masculinities.
\end{abstract}

\section{KEYWORDS}

Homo-social; masculinity; crisis; Clough; biopic 
Networking Knowledge: Journal of the MeCCSA Postgraduate Network, Vol. 4, No. 1 (2011)

As evidenced in The Damned United (Tom Hooper 2009 UK) and The King's Speech (Tom Hooper $2010 \mathrm{UK} / \mathrm{Aus} / \mathrm{US}$ ), a recent trend in the British biopic focuses on the male historical figure, whereby the subject experiences a professional crisis which he can overcome only through a special homo-social bond. The Damned United, based on the David Peace's eponymous novel, represents the brief, unsuccessful period in 1974 when former footballer and successful football manager Brian Clough (Michael Sheen) replaced Don Revie (Colm Meaney) at Leeds United, without the support of his assistant Peter Taylor (Timothy Spall). Represented through a mixture of flashback and the 'present day' of the film, Clough's problematic 44 days with Leeds are contrasted with his earlier success achieved as Derby County manager with Taylor as his assistant in 1968. The King's Speech purports to examine the private world of the monarchy behind the closed doors of Buckingham Palace. It focuses on how a speech impediment suffered by the future king, George VI (Colin Firth) was overcome through his close bond with speech therapist Lionel Logue (Geoffrey Rush). Unlike The Damned United the narrative is linear in structure; the film begins in 1925 when the future King delivers a tortuously laboured speech at Wimbledon stadium, traces his meeting with Logue and their stormy relationship, the accession to the throne, through to the climatic resolution when, with Logue at his side, he broadcasts a heart stirring address to the nation on the advent of World War II. As I will elaborate, despite different historical settings and narrative structures, the narrative drive of both films hinges on similar representations of intimate male friendships which trace a trajectory of professional support, relationship breakdown followed by a restitution characterised by an emotional intimacy and deep level of trust that prefigures the success of the famous historical figure.

The Damned United is not an isolated example of a British football film and other recent examples also represent group homo-social bonds. For example, Best (Mary McGuckian 2000 UK), the biopic of former Manchester United player George Best, locates this famous football star in the masculine dynamics of club and league competition, The Football Factory (Nick Love 2004 UK) which through its focus on both the field and the terraces examines masculine bonds between players, fans and the hooligan element, whilst the fictional Goal (Danny Cannon 2005 UK/US) traces similar terrain in the rise to stardom of a young boy playing for Newcastle. Unlike other football films which focus on group homosocial bonding, The Damned United is an isolated case of a recent football film that explores homo-social bonding between a couple. As Justin Wyatt argues, films which use sports as a 
Networking Knowledge: Journal of the MeCCSA Postgraduate Network, Vol. 4, No. 1 (2011)

setting have a male institutional base that makes them suitable for displaying such male bonds:

The male group and bonding between individual males within that group are central to those films with a strong male institutional base: generically the war film, western, police/detective film, as well as variants such as the prison, fraternity or sports film (2001: 52).

Moreover, the football film in general, and The Damned United in particular, expose the extent to which masculine bonds are shaped and regulated by discourses of machismo - its code of honour underpinned by a drive to secure respect through domination and control. Anthony Clare suggests that:

Such men rate highly their competitiveness, their pride, their strength, their independence, their refusal to be pushed around...Their very honour as men is at stake in every challenge, in every act of disrespect. Such men are truly men only if they are prepared to fight like men. (2000: 36)

However, while the representation of Clough in The Damned United displays these machismo characteristics, they are also shown to be damaged after he experiences a professional crisis. The film suggests that this has its roots in Clough's hatred and obsession with Revie which are established in a scene where Clough waits to welcome the opposition, led by his then hero Revie, to Derby Football Club for an FA cup tie in January 1968. A sequence in which Clough personally instructs cleaners to clean the stadium and the groundsman to tend to the pitch is indicative of both Clough's controlling tendencies and the respect in which he holds Revie; his desire to win his favour. However, on arrival, without a glance in Clough's direction, Revie walks past the outstretched hand of welcome. Effectively, Revie refuses to acknowledge his presence, damaging Clough's pride, and failing to show him due respect under the codes of machismo which is compounded when Revie's Leeds physically dominate the Derby team and win the game. This serves as the trigger for the hatred and obsession that Taylor is unwilling and/or unable to share, sowing the seeds of a rift that prompts a masculine identity crisis.

It is possible to also argue for the existence of a homo-social bond between Clough and Revie in The Damned United, a bond generated through rivalry. Eve Sedgwick has written extensively on homo-social bonds in literature, and observes that bonds formed 
Networking Knowledge: Journal of the MeCCSA Postgraduate Network, Vol. 4, No. 1 (2011)

through rivalry can be as powerful as those bonds formed through love. Writing of René Girard's study 'Deceit, Desire and the Novel,' Sedgwick comments:

What is most interesting for our purposes in his study is its insistence that, in any erotic rivalry, the bond that links the two rivals is as intense and potent as the bond that links either of the rivals to the beloved: that the bonds of 'rivalry' and 'love,' differently as they are experienced, are equally powerful and in many senses equivalent (1985: 21).

With this is mind, I return to the scene in which Revie fails to notice Clough upon his arrival at the Derby stadium after Clough's extensive preparation for the Leeds manager's arrival. Previously, Clough's actions and comments have signalled his respect for the other manager. Then the montage displaying Clough's various actions around the Derby ground signifies his desire to impress him. Revie's lack of reaction at the gate is ambiguous; either he deliberately ignores Clough or fails to recognise a less successful manager coaching a team in a lower league. I have discussed this in terms of damaged machismo; however through applying Sedgwick's analysis Clough can equally be seen as a lover spurned by his object of desire, the spurning fuelling the rivalry. Revie embodies what Clough wishes to achieve: recognition, success and manager of the top team in the country. Clough is obsessed with Revie's position, and the rivalry between the two managers is generated through the desire to occupy the same space. As the game between Derby and Leeds is played, the camera remains on the dugout, where Clough stares across at the opposite dugout where Revie is sitting, a signal of how Revie's lack of recognition goes beyond the professional football rivalry and has affected him personally. Clough has already displayed prior to the match his obsession with Revie's achievements through dialogue and actions. After the game Clough comments to Taylor how they must beat him at all costs, beat him and not Leeds. What began as an obsession with another manager based on shared similarities and respect becomes a darker form of obsession, based on the desire to fill another's space. Following on from Sedgwick's description, Clough and Revie's erotic rivalry translates into rivalry for a space only one figure can occupy.

Later in her study Sedgwick again draws on literary representations, using Great Expectations, Our Mutual Friend and Edwin Drood as examples, suggesting:

...each of these novels sites an important plot in the triangular, heterosexual romance - in the romantic tradition - and then changes its focus as if by 
compulsion from the heterosexual bonds of the triangle to the male homo-social one, here called 'erotic rivalry.' In these male homo-social bonds are concentrated the fantasy energies of compulsion, prohibition and explosive violence, all are fully structured by the logic of paranoia (1985: 162).

The failure by Revie to acknowledge Clough causes a switch in focus to an intense homosocial rivalry. Instead of a desire for the space Revie occupies, the rivalry is instead fuelled by the desire to beat the figure of Revie, more than merely filling the space he occupies as most successful English manager and leader of England's best team. Following this incident in which Revie ignores Clough and a crisis of machismo is triggered, a possibility of restoration is offered when Taylor aids Clough by finding the players who will win the second division league and take them closer to Leeds in Division One. However, Clough is entrenched and continues to display characteristics that resonate with Clare's definition of machismo commented on earlier. He displays strong desire for control of Derby football club by sanctioning the purchase of players without consulting the chairman Sam Longson (Jim Broadbent). When confronted by the chairman he justifies his actions by claiming it is for the benefit of the club when it is equally insinuated that these player purchases will allow Derby to compete with Revie's Leeds on more equal terms, making it a personal vendetta. This view is further consolidated when Clough fields his strongest side against Leeds despite Derby having to play a financially lucrative and prestigious European tie a few days later. Longson confronts Clough, but Clough remains unwilling to compromise and Derby then lose the European game. In his final action as Derby manager Clough issues an ultimatum to the Derby Board, and includes the unknowing Taylor: an ultimatum stating they want an increased control over transfers and tactics or they will resign. When this ultimatum is subsequently rejected Clough's refusal to compromise and his inflexibility with Longson reveal a macho recklessness so fiercely competitive that it brings his downfall.

In subsequent dialogue, Taylor describes to Clough the damaging, dualities of personality that he recognises in him 'Sometimes it's good. Oh, yes. Like a fire that stirs everything up. Then there's this. This thing that takes over. Destroys everything good in your life.' (The Damned United 2009). This clearly resonates with Sedgwick's account of an erotic rivalry based on compulsion and explosive violence. Clough's actions display a dark obsession with Revie, one that influences all his actions, and ultimately causes the breakdown in relations between himself and Taylor. Having both been dismissed at Leeds, the bond between them is ruptured. Taylor goes on to manage Brighton football club whilst Clough is 

(2011)

offered the Leeds management position that he sees as an opportunity to better Revie, by occupying his space, by outperforming him and thus overcoming him.

Clough's obsession to replace and outshine Revie is evidently charged with the fantasy energies described by Sedgwick. This further escalates when Clough, in his first board meeting at Leeds, criticises the both former manager Revie and the current players claiming they have only won football honours through cheating. Without Taylor as a buffer, Clough's 'plain speaking' is exposed as an abusive instance of machismo inflexibility and failure to communicate The ultimate dismissal comes as no surprise and serves to foreground Clough's dependency on the mediations of Taylor. At this point, the representation of Clough's successful machismo begins to slide into one of failure and crisis. John MacInnes' description of masculinity in crisis is useful here:

What were once claimed to be manly virtues (heroism, independence, courage, strength, rationality, will, backbone, virility) have become masculine vices (abuse, destructive aggression, coldness, emotional inarticulacy, detachment, isolation, an inability to be flexible, to communicate, to be soft, supportive or life-affirming (1998: 47).

So, rather than producing a machismo image of Clough as confident, courageous and heroic, The Damned United suggests that those same traits can be identified as 'masculine vices'. These vices then contribute to Clough's alienation when the league competition begins and the poor results come. The team no longer acknowledge him and complain directly to the board about a lack of preparation before the matches, compared to the extensive routines performed by Revie. He realises that he cannot lead these players like those at Derby; they are Revie's players and loyal to him. Clough's growing detachment and decline are shown through late-night drunken telephone calls to Revie and Taylor, which he conducts from a Leeds hotel room where he stays, isolated from his family. He tells Revie that the team will not obey him and then pleads with Taylor to help him, to tell him who to buy as he starts to realise the extent of his reliance on his assistant. In the ultimate act of disempowerment he is sacked for the second time in quick succession and left unemployed. At rock bottom, his road to rehabilitation begins through a recovery of the film's other homo-social bond. He journeys to Brighton and in a strikingly melodramatic scene begs for Taylor's forgiveness, pleading, 'Please baby, take me back.' 

(2011)

The homo-eroticism suggested by this dialogue is prefigured through the flashbacks used to depict Clough's relationship with Taylor and establish their joint success as a football 'marriage.' At various moments within the film the two figures perform certain actions and gestures that are physically intimate, acts such as kissing, or declaring love, hugging, dancing and feeding each other. These actions complicate their identity as heterosexual males, a heterosexuality we are only aware of through certain, limited scenes which show them eating with their family or celebrating successes with them. Justin Wyatt displays a concern with the boundaries between homo-social and homosexual when he asks:

...what about those cinematic cases that cannot be typed so readily - films falling supposedly within the domain of straight male friendship yet which cannot adequately contain the threat of homo-social bonding? (2001: 55)

The intimacy represented between Clough and Taylor in The Damned United certainly fits the uncertainties suggested by Wyatt. Before I elaborate on how Clough's crisis at Leeds is only overcome through the restoration of the bond between Taylor and himself, I want to note similar homo-social, erotic dynamics in the represented bond between George VI and Lionel Logue in The King's Speech.

Set in the inter-war period, The King's Speech offers few locations and few characters with most of the action taking place in Logue's office between the two men. Just as The Damned United implies insider knowledge of the Clough/Taylor partnership of 1968 and Clough's solo stint at Leeds, The King's Speech holds out the promise of 'behind the scenes' revelations of British royalty. The King's Speech employs muted colour which reflects how the audience's understanding of the period is generated through black and white news reel footage and faded photographs. The Damned United also adopts a different aesthetic; vibrant colours are used and in marked contrast to the slow-paced The King's Speech, the action is fast paced whilst being filmed in multiple locations. Equally, the central figures in each film are represented as having different motivations for achieving success. Clough's motivation lies in a regional, working-class rivalry with the manager of Leeds he replaces, whereas the King is motivated by national duty to take the throne and lead the nation through World War II.

Yet despite different characterisations, historical settings and aesthetic codes, both films are similar in that they display male historical figures at critical moments in their lives. 

(2011)

Both depict a man in crisis, and suggest that this crisis can only be overcome through the intervention of another man with whom they share a special homo-social bond. In each case the crisis is centred on a failure to communicate - in The Damned United it is configured as Clough's macho inability to negotiate whilst, through a focus on microphones and radio technologies, The King's Speech highlights the speech impediment that hampers the king's ability to communicate with nation and Empire. The opening scene displays Prince Albert or 'Bertie,' as he is known privately amongst the royal family, failing to address a full Wembley stadium at the close of the British Empire Exhibition in 1925. The thousands in attendance at the stadium hear and witness the stammer which impedes him, whilst the microphone image that fills the screen and effectively dwarfs the prince offers a powerful evocation of the radio audience that extends to the millions of subjects constituting nation and Empire. With the future king's speech established as a problem his wife Elizabeth, the future Queen (Helena Bonham Carter), enlists the help of Australian Lionel Logue to provide speech therapy for her husband. Following regular meetings in which breathing and speaking exercises are performed by a reluctant Bertie a homo-social bond is forged between the two men. As with the Clough/Taylor relationship, the physical intimacy of these consultations unsettles the boundaries between the homo-social and homosexual. Eventually, Logue's unconventional methods begin to have an effect and Bertie confides the traumatic childhood experiences that Logue believes are the root of his stammer and lack of confidence. Bertie is represented as having experienced a childhood that was regimented and militarised and devoid of love. Typically for a wealthy Victorian household he was physically and emotionally distanced from both parents. Yet, his father's domineering will and machismo control dominated the nursery where he was also neglected by the nanny employed to care for him. Through dialogue and flashbacks we learn how he was forced by his father to use his right hand despite naturally favouring the left whilst metal splints were inserted in his legs to combat a 'knock knees' condition. These experiences establish that Bertie's childhood was hugely traumatic because of the machismo culture inculcated by his father. Even after admitting these experiences, the bond between Bertie and Logue is still fragile: following the ascent to the throne of Edward VI (Guy Pearce) and his subsequent abdication the relationship between Bertie and Logue collapses. The relationship is restored when Bertie swallows his pride and approaches Logue for reconciliation. As in The Damned United, the more powerful male figure is humbled and forced to apologise in order to restore a vital homo-social bond. With the friendship recovered, Logue continues to foster the transformation of Bertie into George VI through an unflinching support in speaking at major public events such as the Coronation 
Networking Knowledge: Journal of the MeCCSA Postgraduate Network, Vol. 4, No. 1 (2011)

at Westminster Abbey and the final scene of that represents the iconic wartime broadcast of ‘the king’s speech' from Buckingham Palace on September 1939.

The motif of the 'special' friend is a staple of the biopic. Writing about American biopics pre1960, George F. Custen observes that the represented biopic subject would draw help from a close friend or receive wisdom at a crucial time when the figure themselves was in crisis. Custen writes:

Often, the famous figure shown in a negative light is one who has lost touch with the neighbourhood and old friends. Old friends are often touchstones, reminding heroes, living in some stratosphere, that they generally came from a less exalted sphere (1992: 69).

It is therefore not unusual for the biographical subject to have a close friend upon whom they can rely and receive guidance from when they are lost, and as Custen also suggests " $[\mathrm{t}] \mathrm{he}$ presence of an older figure, the bearer of conventional (sometimes limited) wisdom is a staple of many cinematic biographies" (1992: 69). What makes The Damned United a curious case is that Taylor is not represented as a mere touchstone or old friend, but very much an equal partner in a football marriage. Similarly in The King's Speech Bertie cannot succeed in the public performance of modern, mediated Kingship without the help of Logue. Both examples complicate Custen's model and show a recent development in the genre that his pre-1960s study could not anticipate. Custen writes "[s]elf-creation, the free development of talent through the will of an individual who is detached from a family, is the dominant biopic credo" (1992: 154). Through will alone Clough will not succeed; he needs the player-finding skills of Taylor. For Bertie, the rights of succession are insufficient grounds for the transformation from prince to king: he needs the loyal support of a skilful and innovative therapist. Therefore it seems only fair to discuss these biopics as films that focus on the lives of two historical figures, whose achievements are intertwined. These films are tales of great men plural rather than the singular great man.

One particular incident displays the closeness of the bond shared by Clough and Taylor, when Clough eats dinner with his wife and children in their kitchen before being interrupted by a telephone call from Taylor. The parents sit at each end of the table, and the three children sit between them. This positioning serves to emphasise Clough as husband, father and family man, his heterosexuality confirmed by the presence of his children. 

(2011)

However their eating is interrupted by the sound of the telephone off-screen in the hall. Clough interrupts the family dinner to answer the telephone, sending a signal of Taylor's importance above the family and Taylor's ability to penetrate the private space of their family house. As they discuss a possible transfer target, Taylor looks around to make sure his family (who are eating dinner as well) are not listening. Clough then does the same, looking round to ensure his wife cannot hear their secretive conversation about transfers. The talk is conducted in whispers, which adds to the sense of collusion; it is a talk reserved for each other, but not the family. Both figures are then called back to the dinner table by their wives, but when Clough's wife walks to the hall she realises her husband has gone. The next scene opens within the car as both Clough and Taylor laugh, the camera positioned in the middle back seat. They debate the transfer target and Taylor feeds Clough crisps as he drives, the crisps a substitute for the family meal Clough is neglecting.

Consider how a similar scene of collusion is performed in The King's Speech. While Bertie has a therapy session in Logue's living room, his wife, the future Queen Elizabeth, waits in the adjoining dining room. However Logue's wife, Myrtle (Jennifer Ehle) returns to the house earlier than expected. This unsettles Logue as he fears his wife will be overawed when she discovers the future Queen of England in her dining room. The two men lurk out of view, behind the door that joins the two rooms. Bertie informs his therapist that he should overcome his fear, their roles temporarily reversed. As they whisper between themselves about their wives' mutual reactions the sense of collusion is heightened and further develops their special bond. As in The Damned United, the wives are placed in rooms other than those occupied by their husbands, they operate on the margins of the male couple and thus allow intimate male friendships to exist while also maintaining the heterosexual identities of both sets of male subjects.

The scene in The Damned United shows Clough's two partners, one at home and one at work, and the ease with which the family life can be disturbed by the other. The actions of feeding and drinking highlight the physical intimacy they both share, actions that complicate their position as heterosexual males. Michael A. Messner considers how men can distance themselves from each other by organising their time together around external activities such as sport. Messner writes:

Here men can enjoy the company of other men - even become 'close' - without having to become intimate in ways that may threaten their firm ego 'boundaries', and their fragile masculine identities (2001: 254). 
With this in mind it is useful to consider further incidents and show how the physical intimacy present within the film is never threatening to the heterosexual identities of these figures. Having bought three players on Taylor's advice with the aim of getting Derby out of the second division and into the first to combat Leeds, Taylor and Clough watch the new players practising. Clough praises Taylor for finding these players and enquires how Taylor knew they would be successful. Clough, delighted at the competitive edge this will offer the team, proclaims Taylor a genius, then pulls him close and kisses him hard on the cheek. Perry Garfinkel perfectly encapsulates this construction of the Taylor/Clough friendships: "Our bonds come from doing together; we have not learned about being together" (1985: 3). A similar rupture to the security of the homo-social boundary occurs when Clough, Taylor, their wives and their players are celebrating winning the second division championship. Clough begins singing "Love and marriage," a Frank Sinatra song that connotes the machismo homosocial bond between the rat pack members characterised by 'masculine' traits of heavy drinking and womanising. Clough beckons Taylor to the middle of the room to join him in a dance. As wives and players form a circle around them, they hold each other, the camera follows their movements around the room, privileging this relationship over those with their seemingly accepting wives. The King's Speech establishes a similar intimate, homo-social dynamic. For instance it is Logue, and not the Queen, who is with Bertie in the radio room in Buckingham Palace as he makes the historical outbreak of war address to the nation and Empire. It is Logue who hears Bertie's revelations of a traumatic childhood and it is Logue who is the supportive companion when Bertie finally succeeds at public speaking. The scene is located in the isolated, confined space of an ad hoc broadcasting studio at the palace, the camera cuts between extreme close ups of the two men, establishing an exchange of looks suggestive of an intense, emotional bond. Meanwhile, the Queen is relegated to a marginal, attendant status as she waits, and listens, with the children in an ante-room, bearing witness to the success of the special male bond, just as the wives in The Damned United bear witness to that between Clough and Taylor. In The King's Speech, the positioning of the male friend in the broadcasting studio juxtaposed to the supportive family in the next room makes the kind of distinction between the professional sphere and the domestic sphere suggested in The Damned United. Crucially, Bertie's crisis and vulnerability are resolved through a similar pattern of male bonding and an aligned masculine professional environment that excludes the feminised support of the family like that represented between Clough/Taylor. In each film, 

(2011)

though pushed to the margins, the presence of wives secures the heterosexual identities of the male protagonists, while allowing, and sanctioning, this intimate male bond. This pattern is evident in a scene heavily trailed in the film's publicity where the future Queen sits on Bertie's back while he is practising breathing exercises in Logue's office. Here, she is used as a weight to secure the effectiveness of the exercise and as a weight that secures the future King's heterosexuality. In both films the special relationship between the two men excludes all other characters, including their wives. These bonds are accepted by the wives and create a distinction between subordinate, feminised domestic partners and privileged, masculinised professional partners.

In the closing scene of The Damned United, prior to archive newsreel footage of the actual manager/coach partnership lifting the European trophy, Clough lets down his guard and acknowledges his dependence on Taylor. On his knees in front of Taylor, positioned on the drive of Taylor's house in Brighton, he becomes submissive. In a knowing display of how their relationship is perceived by others, and themselves, Taylor orders Clough to repeat the words "Please baby, take me back." Over the course of the film many instances reveal Clough's egotism, his macho belief in himself and his capabilities. As argued above, these characteristics contribute to his inflexible position when dealing with others and the inability to communicate that leads to his self-destruction at Leeds. However in the final critical scene, when he is been disempowered and suffering low self-esteem, he is finally shown as an emotional being willing to expose his vulnerabilities and needs. The benefits of this therapeutic crisis are encapsulated in the final images of Clough lifting European trophies, of being the ultimate, successful competitor. This chimes with Michael Mangan's account of masculine crisis. Mangan writes:

Crisis is...a condition of masculinity itself. Masculine gender identity is never stable, its terms are continually being re-defined and renegotiated, the gender performance continually being restaged. (2003:4)

The process of re-defining masculinity occurs within the film as Clough gradually reaches the conclusion that he cannot manage Leeds alone and finally admits that he needs Taylor. Compare the first meeting between the Leeds board and Clough, and the final scene in which Clough grovels at the feet of Taylor begging for forgiveness. In the board meeting Clough states his intentions for Leeds, how he wishes to erase the successes of previous manager Revie, whom he loathes and is completely obsessed with in equal measure. Framed in a head 

(2011)

and shoulder shot in his seat, Clough announces that soon "the ale houses of Yorkshire" (The Damned United 2009) will be singing his name and not Revie's. With this statement he winks and grins smugly at the board, displaying a lack of respect for those in control of the football club and an arrogance when being compared to other males in his profession. However, in the final scene this egotism has left him, and he openly admits his dependence on Taylor. The film shows this transition from arrogance, deluded self-confidence and fierce rivalry to a weakened, broken man admitting he needs someone else. Furthermore Clough's actions and words in this scene complicate Garfinkel's earlier statement, as over the course of the film Clough has realised his level of reliance on Taylor and learnt the importance of being with him and not just doing with him.

The submission of Clough to Taylor contrasts with earlier scenes where first Derby and then Leeds board members are unable to control him as he disobeys them and vies for increased control of the club. John Beynon's account of emerging modes of masculinity is useful here. He suggests " $[\mathrm{m}]$ any remain bad at acknowledging and expressing feelings and are trapped between old style, machismo and nurturing 'new man-ism'" (2001: 77), a statement which holds resonance with how Clough changes over the course of the film, moving from machismo at the start of the film towards a new man-ism. Crucially however, Clough has been reconstituted into 'new man-ism' through the structures of the male dominated professional sphere of football and not the domestic sphere of wife and family. Clough achieves his transformation through another male subject and by doing so will win European trophies and achieve professional success in a macho culture rather than a feminised usually associated with 'new-man' identities. Notably, the machismo displayed by Clough remains intact and the course of the narrative it is reconfigured rather than subsumed into femininity. Through this, Clough becomes constructed as a 'new new man.'

The King's Speech displays a similar road to successful leadership as prefigured by scenes of humility, of breaking down in front of a male friend in order to be re-built into a successful leader. One particular scene between Bertie and Logue can be seen as a crucial moment in his overcoming his stammer and fear of becoming King, a scene similar to that shared by Clough and Taylor in Brighton. Bertie arrives at Logue's workplace after the abdication of his brother, Edward. After the death of George $\mathrm{V}$ their relationship had broken down, when Logue stated that Bertie was capable of becoming king should his brother abdicate. The pair parted after Bertie accused Logue of treason and cruelly mocked Logue's failed acting career. At the instigation of his wife who realises that the relationship is much 

(2011)

more than therapist and client, Logue pays a visit to Bertie with a view to repairing their bond, but he is 'not received.' Space does not permit a discussion of the gender binary in the film but it is noteworthy that Mrs. Logue reiterates the dominant stereotype of 'instinctive' feminine intuition: an intuition that must be learned and incorporated into macho masculinity in order to build the successful, male leader. Subsequently, Bertie accepts that he needs Logue and following his rebuff of Logue's attempt at reconciliation, his apologetic visit to Logue's office is rendered all the more demeaning. As with Taylor and Clough, the crisis in the professional bond triggers a crisis of identity for the ostensibly privileged figure of the homosocial bond. Following this scene in which the friendship is repaired, Bertie increasingly relies on the bond with Logue to successfully perform at large events. In a scene set in Westminster abbey, the pair rehearse the King's imminent coronation ceremony. Logue settles on the throne as he commences his therapeutic practice, an act which incenses Bertie who then furiously instructs Logue to remove himself from the Abbey. Logue, who has evidently forced the angry outburst, then forces Bertie to claim his birthright to be monarch: to claim his birthright to exercise the Divine Right of King's. As with Clough, a breakdown in emotional control establishes the basis of professional success. Here, it is worth noting the dual meaning in the film's title which is equally concerned with the actual speech the king will make in 1939 as much as the impediment.

Throughout The King's Speech a famous figure is represented in the process of owning and admitting his flaws to another man. The meetings between the future king and Logue involve 'Bertie' coming to terms with negative childhood experiences embodied in the stammer in order to become King George VI. The close male bond with Logue enables Bertie to banish the low self-esteem he has suffered since childhood and thus deal with his stammer. Where the homo-social bond represented in The Damned United is about building Clough into one of Britain's most successful football managers, the one formulated in The King's Speech is about the constitution of George VI as one of Britain's most beloved kings.

I have suggested that in The Damned United and The King's Speech the friend is not merely some touchstone, like the supportive wife, to aid the singular man in his quest for greatness. In both films, the friendship between two men is the crucial component in achieving professional success. Wives are present but play peripheral figures in terms of the support they provide to the male characters, and they accept the bond formed between the two men. The distant, though always present role performed by the wives in both films secures the heterosexual identities of both male figures and in doing so allows intimate homo-social 
Networking Knowledge: Journal of the MeCCSA Postgraduate Network, Vol. 4, No. 1 (2011)

bonds to exist outside gay culture. These close bonds allow for emotional reliance on another male in a heterosexual context and in doing so open up the possibilities of deeply emotional male friendships that are not couched in homosexual discourses and which constitute a new formation of 'new man-ism'.

In both films the leading figure must be broken down through a crisis and then be rebuilt through the aid of another man. In order to achieve professional success both male figures must admit their dependence on another man. Both men must overcome the sense of honour that inflicts them and both must ask another man for help in order to do so. Their task is to become new 'new men', men constituted through discourses of professional success and not through the 'new man' discourses of domesticity. Andrew Spicer writes "[t]he New Man was an alternative image to the macho tough guy, embracing female roles and qualities, a vulnerable nurturer in touch with his emotions, but also rather narcissistic" (2003:187). But in The Damned United and The King's Speech, machismo and 'new man-ism' are not represented as alternatives but as a necessary fusion that heals a crisis occasioned by damaged masculinity. 
Networking Knowledge: Journal of the MeCCSA Postgraduate Network, Vol. 4, No. 1 (2011)

\section{Bibliography}

Beynon, John (2001) Masculinities and Culture. Buckingham: OU Press.

Clare, Anthony (2000) On Men: Masculinities in Crisis. London: Chatto \& Windus.

Custen, George (1992) Bio/Pics. New Jersey: Rutgers University press.

Garfinkel, Perry (1985) In a Man's World: Father, Son, Brother, Friend and Other Roles Men Play. California. Berkley: Ten Speed Press.

MacInnes, John (1998) The End of Masculinity. Buckingham: Open University Press.

Mangan, Michael (2003) Staging Masculinities: History, Gender, Performance. Basingstoke: Palgrave Macmillan.

Messner, Michael A (2001) 'Friendship, Intimacy, Sexuality' in Whitehead, Stephen and Barret, Frank (eds.) The Masculinities Reader. Cambridge: Polity Press 253-265.

Sedgwick, Eve (1993) Between Men: English Literature and Male Homo-social Desire. New York: Columbia University Press. 
Networking Knowledge: Journal of the MeCCSA Postgraduate Network, Vol. 4, No. 1 (2011)

Spicer, Andrew (2003) Typical Men: The Representation of Masculinity in Popular British Cinema. London: I.B. Tauris.

Wyatt, Justin (2001) “Identity, Queerness and Homo-social Bonding” in Lehman, Peter (ed.) Masculinity: Bodies, Movies, Culture. London: Routledge. 51-65.

\section{Filmography}

Best (Mary McGuckian 2000 UK)

Damned United, The (Tom Hooper 2009 UK)

Football Factory, The (Nick Love 2004 UK)

Goal! (Danny Cannon 2005 UK/US)

I love you, Man (John Hamburg 2009 US)

King's Speech, The (Tom Hooper 2010 UK)

Knocked Up (Judd Apatow 2007 US) 